\title{
Trends in Direct-to-Consumer Advertising of Prescription Contraceptives
}

\section{Citation}

Wu, Min. 2016. Trends in Direct-to-Consumer Advertising of Prescription Contraceptives. Doctoral dissertation, Harvard Medical School.

\section{Permanent link}

http://nrs.harvard.edu/urn-3:HUL.InstRepos:40620273

\section{Terms of Use}

This article was downloaded from Harvard University's DASH repository, and is made available under the terms and conditions applicable to Other Posted Material, as set forth at http:// nrs.harvard.edu/urn-3:HUL.InstRepos:dash.current.terms-of-use\#LAA

\section{Share Your Story}

The Harvard community has made this article openly available.

Please share how this access benefits you. Submit a story.

Accessibility 


\title{
Trends in direct-to-consumer advertising of prescription contraceptives
}

\author{
Min H. Wu ${ }^{\mathrm{a}, \mathrm{b}, *}$, Deborah Bartz ${ }^{\mathrm{a}, \mathrm{c}}$, Jerry Avorn ${ }^{\mathrm{a}, \mathrm{b}}$, John D. Seeger ${ }^{\mathrm{a}, \mathrm{b}}$ \\ ${ }^{\mathrm{a}}$ Harvard Medical School, Boston, MA 02115, USA \\ ${ }^{\mathrm{b}}$ Division of Pharmacoepidemiology and Pharmacoeconomics, Department of Medicine, Brigham and Women's Hospital and Harvard Medical School, \\ Boston, MA 02115, USA \\ ${ }^{\mathrm{c}}$ Department of Obstetrics, Gynecology, and Reproductive Biology, Brigham and Women's Hospital, Boston, MA 02115, USA \\ Received 13 August 2015; revised 20 January 2016; accepted 20 January 2016
}

\begin{abstract}
Objective: Despite much speculation about the role of direct-to-consumer advertising (DTCA) in increasing demand for prescription contraceptives in the United States, there is little published research on this topic. We sought to quantify the prevalence and magnitude of DTCA for prescription contraceptives over the last decade.

Study design: Using cross-sectional data from January 2005 through December 2014, we performed descriptive analyses on trends in DTCA expenditure for prescription contraceptives. We also quantified the amount of DTCA according to contraceptive method category and individual brand.

Results: During the study period, pharmaceutical companies spent a total of US\$1.57 billion in the United States on DTCA of prescription contraceptives. Annual expenditure for contraceptive DTCA reached a peak value of US\$260 million in 2008, with a progressive decline to a nadir of US\$69 million by 2013. Of the contraceptive methods, oral contraceptive pills (OCPs) have been the most heavily promoted, with Yaz (drospirenone/ethinyl estradiol) — the most advertised brand - accounting for US\$347 million of cumulative DTCA expenditure. However, DTCA spending on OCPs peaked in 2007 and was overtaken in 2012 by the DTCA of long-acting reversible contraceptives (LARCs), the contraceptive method now receiving the largest amount of DTCA promotion.

Conclusions: DTCA is a major form of promotion for prescription contraceptives. Recent trends in DTCA expenditure indicate a shift from promotion of the OCPs to the LARCs. DTCA's effect on provider and patient utilization of various contraceptive methods has yet to be determined.

Implications: This study provides the first quantitative evaluation of DTCA of prescription contraceptive methods and reveals DTCA's importance as a form of promotion. Recent DTCA trends indicate increased promotion of LARCs, coinciding with greater uptake of LARC methods by patients and prescribers.
\end{abstract}

(C) 2016 Elsevier Inc. All rights reserved.

Keywords: Direct-to-consumer advertising; Prescription drugs; Long-acting reversible contraceptives; Contraception; Contraceptive devices

\section{Introduction}

Following its rapid growth since the 1990s, the direct-toconsumer advertising (DTCA) of prescription pharmaceuticals has been controversial. Proponents claim that DTCA serves as a form of patient education, providing information about potential care options and increasing medical literacy, while destigmatizing certain medical conditions such as depression

\footnotetext{
* Corresponding author.

E-mail addresses: min_wu@hms.harvard.edu (M.H. Wu), dbartz@partners.org (D. Bartz), javorn@partners.org (J. Avorn), jdseeger@partners.org (J.D. Seeger).
}

or erectile dysfunction [1-4]. However, critics argue that DTCA promotes misleading information to a vulnerable patient population, falsely inflating demand for newer and more expensive - but not necessarily more effective medications [2-6]. Given the substantial arguments against it, DTCA is banned in the vast majority of the 34 countries in the Organization for Economic Co-operation and Development and is currently allowed only in the United States and New Zealand $[2,6,7]$.

Industry expenditure on DTCA in the United States increased 330\% from 1996 to 2005 [8], peaking in 2006 at an estimated US\$5.89 billion [9]. Despite this growth, DTCA constitutes but a small percentage (consistently less than $20 \%$ ) of pharmaceutical promotional expenditure, with the 
larger proportion of advertising spending going toward promotion to professionals, such as physician detailing, free samples and professional journal advertisements [8-10]. Economic analyses have found intriguing differences between DTCA and professional promotion. Unlike professional promotion, which occurs relatively consistently across all branded pharmaceutical products, DTCA is highly concentrated among a small number of top brands $[8,9]$. Furthermore, while professional promotion - detailing in particular - has been found to increase sales of the advertised product, DTCA appears to have a broader effect by expanding the market for an entire drug class, often with limited impact on individual sales for the advertised drug itself [2,10-14].

The DTCA of prescription contraceptives raises unique concerns that warrant greater study. Notably, more so than in other fields of medicine, contraceptive choice relies heavily on patient preference and patient-driven decision-making, often even at the expense of clinical efficacy [15-17]. As such, contraceptive care may be uniquely susceptible to DTCA's influence on demand. In addition, a provision of the Affordable Care Act (ACA) requiring private health plans to cover contraceptive methods without copayments, deductibles or other out-of-pocket costs took effect for millions of Americans in January 2013 [18]. With the elimination of patient cost sharing, DTCA could have an even greater impact on contraceptive demand, especially for methods with substantial upfront costs such as intrauterine devices (IUDs) or the subdermal implant $[18,19]$.

Importantly, the majority of the drugs studied in DTCA literature (e.g., statins and proton-pump inhibitors) have relatively similar efficacies, with individual advertised products having few demonstrable advantages over others in their therapeutic class. In contrast, the prescription contraceptives vary considerably in their level of use effectiveness (as distinct from efficacy), with long-acting reversible contraceptives (LARCs), such as IUDs and subdermal implants, offering substantially superior contraceptive effectiveness to the oral contraceptive pill (OCP), transdermal patch and vaginal ring [19-22]. Therefore, DTCA prompting patients to consider LARC methods has the potential to increase use of more effective forms of contraception, thereby preventing more unintended pregnancies.

There has been much speculation about the role of DTCA as a source of patient information and as a potential driver of recent increased use of particular contraceptive methods, such as the LARCs. Studies examining sources of patient information about contraceptives report that "[t]he majority of women who had heard of LARCs mentioned they had seen commercials on television for the intrauterine contraceptive" [23-25], and reproductive health professionals have drawn attention to the temporal association between DTCA and the substantial growth in IUD use in the United States $[20,26]$.

Despite the potential influence that DTCA may have on contraceptive utilization, there have been no quantitative studies to date on the DTCA of prescription contraceptives.
While there have been qualitative analyses of the content of contraceptive DTCA [27,28], little is known about the magnitude, trends, and effects on demand of DTCA for the contraceptives. This study aims to quantify DTCA expenditure for prescription contraceptives over the last decade, determining (a) the prevalence of DTCA among the contraceptives as a therapeutic class; (b) the amount of DTCA by contraceptive method and individual brand; and (c) the trends in DTCA spending, indicating any potential changes since the enactment of the ACA provision in 2013.

\section{Methods}

\subsection{Data source}

Data for this study were provided by Kantar Media (previously Competitive Media Reporting and TNS Media Intelligence), a private market research and media analysis company tracking advertising spots in 101 television networks, 164 local and national newspapers, 380 magazines, 108 radio channels and 102 outdoor promotions locations. Kantar Media also offers additional data on Internet promotion, but these data were not obtained for our study. Kantar Media calculates US dollar values of industry advertising expenditure using rate cards provided by various media networks, agencies and publishers. All products in the Kantar Media database are organized into hierarchical categories (e.g., "Prescription Medications", "Medicated Products \& Remedies - Non-RX") along with more specific subcategories (e.g., "Prescription Contraceptive Medications", "Prescription Heart, Blood Pressure, and Cholesterol Medications"). It is the primary database used in prior studies of medical DTCA $[8,9,12,14,29]$.

Based on advertising expenditure data from January 2005 to December 2014, we examined DTCA expenditure for all prescription drug products by selecting "Prescription Medications" as our product set. Each DTCA prescription product was linked to its active ingredients, generic availability and Food and Drug Administration (FDA) approval date using the FDA Orange Book. Each product was also assigned to a therapeutic class according to the American Hospital Formulary Service (AHFS) Pharmacologic-Therapeutic Classification system. Contraceptives are either products in AHFS Class 68:12 ("Contraceptives") or 32:00 ["Contraceptives (foams, devices)"].

For the purposes of analyzing DTCA expenditure by contraceptive type, products were categorized as (a) LARCs; (b) permanent contraception; or (c) all other contraceptive methods. The LARCs were defined as any methods lasting greater than 3 months, thereby including the IUDs and subdermal implant but excluding the progesterone-only injectable, a definition consistent with prior studies [20,21]. The permanent contraception category included data on the advertisement of specific products used in permanent contraception, such as the Essure system, and did not include the promotion of individual clinics or services. This three-group division was further separated into subcategories 
Table 1

Annual DTCA for all prescription contraceptive brands, 2005 to 2014

\begin{tabular}{lllllllllll}
\hline & 2005 & 2006 & 2007 & 2008 & 2009 & 2010 & 2011 & 2012 & 2013 & 2014 \\
\hline No. of brands & 7 & 7 & 10 & 8 & 6 & 7 & 8 & 5 & 5 & 5 \\
Total (millions of US\$) & 193.13 & 154.58 & 239.88 & 260.1 & 230.7 & 131.39 & 121 & 73.12 & 68.85 & 96.13 \\
Mean (millions of US\$) & 27.59 & 22.08 & 23.99 & 32.51 & 38.45 & 18.77 & 15.12 & 14.62 & 13.77 & 19.23 \\
Std. dev. (millions of US\$) & 25.13 & 12.21 & 28.72 & 31.10 & 36.37 & 17.49 & 13.92 & 10.99 & 13.18 & 16.77 \\
Max (millions of US\$) & 70.65 & 41.31 & 93.42 & 79.99 & 99.89 & 46.51 & 41.64 & 26.57 & 34.44 & 43.24 \\
\hline
\end{tabular}

Mean and standard deviation values describe the mean and standard deviation for annual DTCA expenditure for all brands with nonzero DTCA spend in the indicated year. maximum values describe the maximum annual expenditure on DTCA for a single brand in the indicated year. All dollars were adjusted to 2014 dollars according to the Consumer Price Index for Medical Care.

Sources: DTCA data provided by Kantar Media.

of contraceptive methods, including OCPs, vaginal ring, transdermal patch, IUDs, subdermal implant, progesterone injectable, permanent contraception or emergency contraception (EC).

\subsection{Analysis}

Using descriptive analyses, we quantified DTCA among the prescription contraceptives as a class relative to other therapeutic classes, focusing on total expenditure on DTCA and number of direct-to-consumer (DTC)-advertised brands. We also quantified DTCA by categories of contraceptive type and by individual brand. All data on promotional spending were adjusted to 2014 US\$ using the Consumer Price Index-All Urban Consumers, Medical Care dataset [30]. The study was approved by the Partners Healthcare System Institutional Review Board.

\section{Results}

\subsection{Class-wide trends in DTCA}

From January 2005 to December 2014, a total of US $\$ 1.57$ billion was spent on DTCA for prescription contraceptives. A total of 21 contraceptive brands were advertised. Class-wide spending on DTCA grew 35\% from US\$193 million in 2005 to a peak of US\$260 million in 2008 (Table 1, Fig. 1). Since then, there has been a decline in DTCA expenditure, with 2013 marking a study-period-wide low of US $\$ 68.9$ million. In 2014, spending on contraceptive DTCA rebounded slightly to US\$96.1 million. The number of brands employing DTCA peaked in 2007 at 10 brands and has declined to a total of five brands in 2014 (Table 1). In comparison to other therapeutic classes, the contraceptives ranked 13th overall in aggregate DTCA spending (Table 2a) and third in the total number of brands advertised DTC during the study period (Table $2 b$ ).

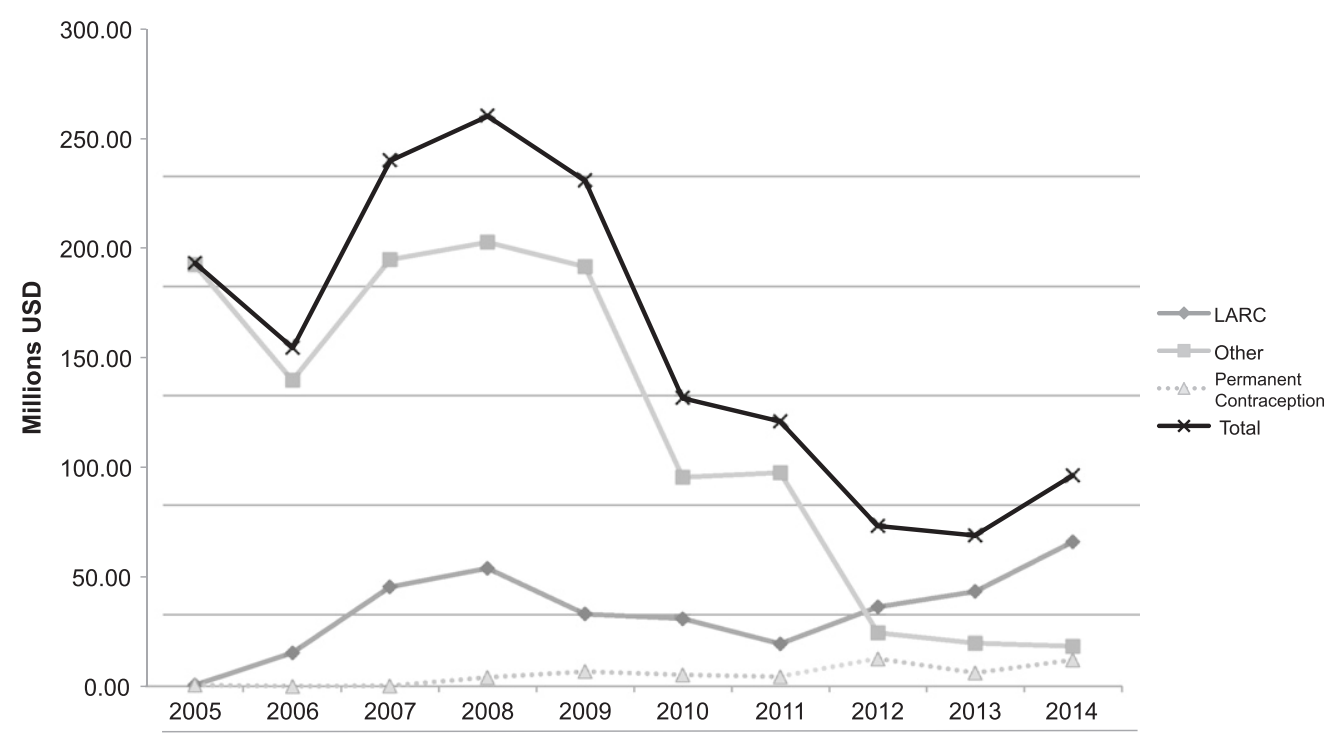

Fig. 1. Annual DTCA expenditure for all prescription contraceptives by contraceptive method. The LARC category contains total DTCA expenditure for IUDs and the subdermal implant. The Other category contains total DTCA expenditure for OCPs, vaginal ring, transdermal patch and EC. All dollars are presented in millions US Dollars (USD) and were adjusted to 2014 dollars according to the Consumer Price Index for Medical Care. Sources: DTCA data provided by Kantar Media. 
Table $2 \mathrm{a}$

Top 20 therapeutic classes of drugs for DTCA expenditure

\begin{tabular}{|c|c|c|c|}
\hline Rank & Therapeutic class & Example brands & $\begin{array}{l}\text { Total spend } 2005-2014 \\
\text { Millions of US\$ }\end{array}$ \\
\hline 1 & Antilipemic agents & Lipitor, Vytorin, Caduet & 4524.97 \\
\hline 2 & Psychotherapeutic agents & Abilify, Prozac, Wellbutrin & 4355.86 \\
\hline 3 & Respiratory tract antiinflammatory agents & Singulair, Advair, Flovent & 3545.46 \\
\hline 4 & Vasodilating agents & Cialis, Viagra, Bidil & 3427.89 \\
\hline 5 & Disease-modifying antirheumatic agents & Humira, Enbrel, Remicade & 3210.47 \\
\hline 6 & Adrenals & Advair, Flovent, Dulera & 2891.54 \\
\hline 7 & Sympathomimetic (adrenergic) agents & Advair, Brovana, EpiPen & 2830.99 \\
\hline 8 & Anxiolytics, sedatives and hypnotics & Lunesta, Ambien & 2666.43 \\
\hline 9 & Antithrombotic agents & Xarelto, Plavix, Pradaxa & 1966.70 \\
\hline 10 & Bone resorption inhibitors & Boniva, Reclast, Zometa & 1826.95 \\
\hline 11 & EENT $^{*}$ antiinflammatory agents & Nasonex, Restasis, Flonase & 1816.54 \\
\hline 12 & Anticonvulsants & Lyrica, Keppra, Horizant & 1574.48 \\
\hline 13 & Contraceptives & Yaz, Nexplanon, Mirena & 1568.88 \\
\hline 14 & Antidiabetic agents & Januvia, Lantus, Avandia & 1379.01 \\
\hline 15 & Genitourinary smooth muscle relaxants & Vesicare, Detrol, Myrbetriq & 1306.54 \\
\hline 16 & Antiulcer agents and acid suppressants & Nexium, Zantac, Vimovo & 1173.66 \\
\hline 17 & Vaccines & Gardasil, Zostavax, Menactra & 1076.79 \\
\hline 18 & Analgesics and antipyretics & Vioxx, Ultran, Suboxone & 963.41 \\
\hline 19 & Autonomic drugs, miscellaneous & Chantix, Nicotrol & 748.77 \\
\hline 20 & Antivirals & Sovaldi, Truvada, Valtrex & 716.61 \\
\hline
\end{tabular}

All dollars adjusted to 2014 dollars according to the Consumer Price Index for Medical Care. Therapeutic classes for DTCA prescription drugs defined by the AHFS Pharmacologic-Therapeutic Classification.

Sources: DTCA data provided by Kantar Media.

* EENT denotes Ear, Eye, Nose and Throat.

\subsection{DTCA trends by contraceptive type}

OCPs were the most advertised type of contraceptive, with a total of US\$786 million (or $50 \%$ of all contraceptive DTCA expenditure) spent on DTCA during the study period (Table 3). The vaginal ring and IUD were the second and third most advertised methods, at US\$316 million (20\%) and US\$265 million (17\%), respectively. The progesterone-injectable was the only contraceptive method that did not advertise to consumers during the entirety of the study period.
Yearly DTCA expenditure for OCPs peaked in 2007 at US\$178 million (Table 3), with a steady decline since: in 2012, manufacturers spent a mere US\$3780 on DTCA for OCPs with no expenditure in 2013 and 2014. Annual spending on DTCA for the vaginal ring has decreased since its peak in 2008 at US\$71.7 million, plateauing at roughly US\$20 million since 2010. DTCA of the IUDs experienced a rapid growth from 2005 to 2008 , rising from US $\$ 411,860$ to a peak of US\$53.7 million, but has declined since. Of note, despite FDA approval of the Implanon subdermal etonogestrel implant in 2006, DTCA of this method only began in

Table $2 \mathrm{~b}$

Top 10 therapeutic classes of drugs by number of brands advertising DTC

\begin{tabular}{lll}
\hline Rank & Therapeutic class & Example brands \\
\hline 1 & Antivirals & Sovaldi, Truvada, Valtrex \\
2 & Antidiabetic agents & Januvia, Lantus, Avandia \\
3 & Antineoplastic agents & Gleevec, Femara, Rituxan \\
3 & Contraceptives & Yaz, Nexplanon, Mirena \\
5 & Devices & Juvederm, Restylane, Hyalgan \\
6 & Vaccines & Gardasil, Zostavax, Menactra \\
7 & Antilipemic agents & Lipitor, Vytorin, Caduet \\
7 & Psychotherapeutic agents & Abilify, Prozac, Wellbutrin \\
9 & Skin and mucous membrane agents, miscellaneous & Stelara, Epiduo, Elidel \\
10 & EENT antiinflammatory agents & Nasonex, Restasis, Flonase \\
10 & Sympathomimetic (adrenergic) agents & Advair, Brovana, EpiPen \\
10 & Estrogens and estrogen agonist-antagonists & Premarin, Evista, Estring \\
10 & Anorexigenic agents and respiratory and cerebral stimulants & Provigil, Adderall, Vyvanse \\
10 & Bone resorption inhibitors & Boniva, Reclast, Zometa \\
\hline
\end{tabular}

Therapeutic classes for DTCA prescription drugs defined by the AHFS Pharmacologic-Therapeutic Classification. Sources: DTCA data provided by Kantar Media. 
Table 3

Annual DTCA spend for prescription contraceptive products by brand and contraceptive method

\begin{tabular}{|c|c|c|c|c|c|c|c|c|c|c|c|}
\hline & \multicolumn{11}{|c|}{ DTCA expenditure (millions of USD) } \\
\hline & 2005 & 2006 & 2007 & 2008 & 2009 & 2010 & 2011 & 2012 & 2013 & 2014 & Total \\
\hline $\mathrm{OCP}$ & 97.65 & 98.01 & 178.01 & 130.67 & 134.55 & 77.84 & 69.35 & $0.00^{*}$ & - & - & 786.09 \\
\hline Yaz & - & 27.68 & 93.42 & 79.99 & 99.89 & 46.51 & - & - & - & - & 347.49 \\
\hline Seasonique & - & - & 21.94 & 17.40 & 34.66 & 29.20 & 12.94 & - & - & - & 116.13 \\
\hline Loestrin $24 \mathrm{FE}$ & - & 33.47 & 36.31 & 15.36 & - & - & - & - & - & - & 85.14 \\
\hline Yasmin & 40.48 & 15.74 & - & - & - & - & - & $0.00^{*}$ & - & - & 56.23 \\
\hline Ortho Tri-Cyclen Lo & 40.51 & 12.95 & - & - & - & - & - & - & - & - & 53.45 \\
\hline Beyaz & - & - & - & - & - & - & 41.64 & - & - & - & 41.64 \\
\hline Lybrel & - & - & 7.29 & 17.92 & - & - & - & - & - & - & 25.21 \\
\hline Seasonale & 16.67 & 8.17 & - & - & - & 0.11 & - & - & - & - & 24.94 \\
\hline Femcon FE & - & - & 18.50 & - & - & - & - & - & - & - & 18.50 \\
\hline Lo Loestrin $\mathrm{Fe}$ & - & - & - & - & - & - & 14.13 & - & - & - & 14.13 \\
\hline Natazia & - & - & - & - & - & 2.02 & - & - & - & - & 2.02 \\
\hline Generess Fe & - & - & - & - & - & - & 0.65 & - & - & - & 0.65 \\
\hline Ortho Tri-Cyclen & - & - & 0.56 & - & - & - & - & - & - & - & 0.56 \\
\hline Ring & 23.86 & 41.31 & 16.51 & 71.71 & 56.64 & 17.43 & 26.30 & 24.42 & 19.52 & 18.22 & 315.93 \\
\hline NuvaRing & 23.86 & 41.31 & 16.51 & 71.71 & 56.64 & 17.43 & 26.30 & 24.42 & 19.52 & 18.22 & 315.93 \\
\hline IUD & 0.41 & 15.26 & 45.22 & 53.65 & 32.93 & 30.82 & 19.24 & 36.03 & 8.77 & 22.77 & 265.12 \\
\hline Mirena & - & 15.26 & 44.54 & 52.99 & 32.45 & 30.82 & 19.24 & 9.46 & 4.13 & - & 208.90 \\
\hline Paragard T $380 \mathrm{~A}$ & 0.41 & - & 0.68 & 0.66 & 0.48 & - & - & 26.57 & 4.64 & 4.65 & 38.10 \\
\hline Skyla & - & - & - & - & - & - & - & - & - & 18.11 & 18.11 \\
\hline Implant & - & - & - & - & - & - & - & - & 34.44 & 43.24 & 77.68 \\
\hline Nexplanon & - & - & - & - & - & - & - & - & 34.44 & 43.24 & 77.68 \\
\hline Patch & 70.65 & - & - & - & - & - & - & - & - & - & 70.65 \\
\hline Ortho Evra & 70.65 & - & - & - & - & - & - & - & - & - & 70.65 \\
\hline Permanent contraception & 0.55 & - & 0.15 & 4.07 & 6.57 & 5.30 & 4.47 & 12.66 & 6.12 & 11.90 & 51.79 \\
\hline Essure & 0.55 & - & 0.15 & 4.07 & 6.57 & 5.30 & 4.47 & 12.66 & 6.12 & 11.90 & 51.79 \\
\hline $\mathrm{EC}$ & - & - & - & - & - & - & 1.63 & - & - & - & 1.63 \\
\hline Ella & - & - & - & - & - & - & 1.63 & - & - & - & 1.63 \\
\hline
\end{tabular}

All dollars are presented in millions USD and adjusted to 2014 dollars according to the Consumer Price Index for Medical Care. Sources: DTCA data provided by Kantar Media.

* Total DTCA expenditure for Yasmin and the OCPs as a class in 2012 was US\$3780.

2013. However, as of 2014, the subdermal implant has overtaken all other forms of contraception to become the most advertised method.

Differentiating by LARC (subdermal implants and IUDs), permanent contraception (Essure) and all other contraceptive methods (OCPs, vaginal ring, transdermal patch and EC) reveals the growth of DTCA for the LARCs since 2012 (Fig. 1). However, despite having the highest expenditure as a category in 2013 at US\$43.2 million and in 2014 at US\$66 million, the LARCs have yet to reach the combined DTCA spending of the OCPs, vaginal ring, transdermal patch and EC at their peak (US\$202 million in 2008; Fig. 1).

\subsection{DTCA trends by individual brand}

Spending on DTCA for the contraceptives is concentrated among a small number of brands, with the top five advertised brands alone accounting for $68.4 \%$ of total contraceptive DTCA spending (Table 3, Fig. 2). Indeed, the rapid rise of DTCA from 2005 to 2008 and its subsequent decline appear to be driven by the advertising campaigns of a few select OCP brands, particularly Yaz (drospirenone/ethinyl estradiol), which dominated DTCA expenditure among the contraceptive brands, accounting for a total of US\$347 million of expenditure (or
$22.1 \%$ of total class-wide spending) from 2006 to 2010 (Table 3). Contraceptive DTCA campaigns vary widely in duration from brand to brand; some, such as Yaz (drospirenone/ ethinyl estradiol), are advertised consistently for 5 years while others, such as Natazia (dienogest/estradiol valerate), are only promoted for 2 months out of the entire study period (Table 3 ).

\section{Discussion}

From January 2005 through December 2014, pharmaceutical manufacturers allocated substantial resources to the DTCA of prescription contraceptives, putting them in the top 20 therapeutic classes for both total DTCA expenditure and the total number of advertised brands. Spending on DTCA for the contraceptives peaked in 2008 at US\$260 million, with a decline in recent years; total DTCA spending in 2014 was only $49.8 \%$ of the amount spent in 2005 . This decrease in contraceptive DTCA expenditure parallels trends in other prescription pharmaceuticals: as of 2010, DTCA spending for all prescription medications had declined $25 \%$ from its peak of US\$5.9 billion in 2006 [9].

Among the prescription contraceptives, as in other previously studied therapeutic classes [7-9], spending on 
M.H. Wu et al. / Contraception $x x$ (2016) $x x x-x x x$

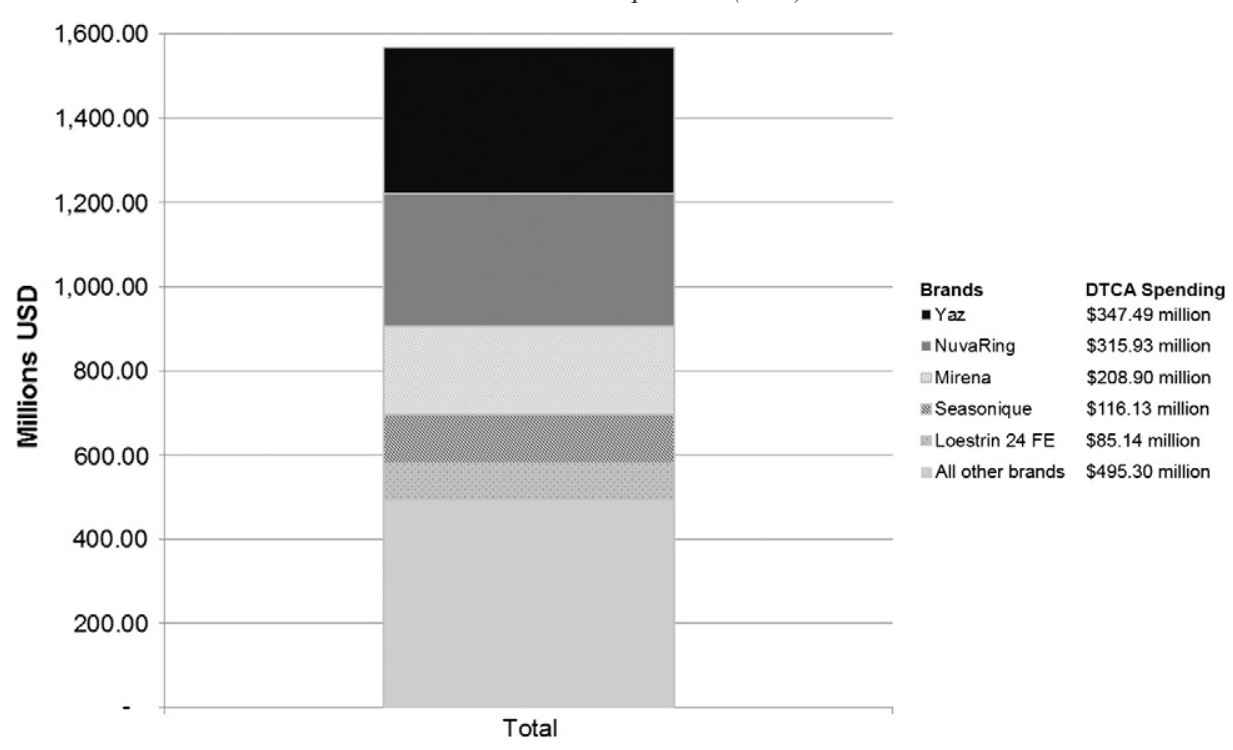

Fig. 2. Total DTCA Expenditure by Brand. This figure depicts the total DTCA expenditure during the study period for the top five advertised prescription contraceptive brands. The "All other brands category" describes the cumulative DTCA expenditure for the remaining 16 prescription contraceptive brands that advertised DTC during the study period. All dollars are presented in millions USD and were adjusted to 2014 dollars according to the Consumer Price Index for Medical Care. Sources: DTCA data provided by Kantar Media.

DTCA is highly skewed and concentrated on a few products, with top brands like Yaz (drospirenone/ethinyl estradiol) accounting for $22 \%$ of total contraceptive DTCA expenditure. As such, the dramatic shifts in overall contraceptive DTCA are not due to changes in spending across multiple brands, but rather are driven by these few top advertisers. For example, the decline in total contraceptive DTCA spending after 2008 coincides with a substantial decrease in DTCA spending on Yaz (drospirenone/ethinyl estradiol) after entry of a generic equivalent in March 2009.

It is interesting to note the increase in consumer promotion of the LARCs beginning in 2012, with significant growth after the first quarter of 2013. The timing coincides with the enactment of a provision of the ACA - phased in during August 2012 and taking broader effect in January 2013 - which is expected to eliminate cost sharing for contraceptive methods and services. While limited in scope, previous studies have found that copayments tend to moderate the effects of DTCA, with higher copayments blunting DTCA's influence [31]. In the wake of the ACA provision's removal of cost sharing for contraceptives, DTCA has the potential to have a significant influence on contraceptive choice. Given this prospect, there may be an impending increase in DTCA among the prescription contraceptives, especially for methods with high upfront costs like the LARCs $[18,19]$. Future studies tracking contraceptive DTCA expenditures over a longer period of time may be able to more clearly illustrate the effect of the ACA provision on contraceptive DTCA.

The recent increase in DTCA of the LARCs also coincides with growing utilization of these methods in the United States. From 2002 to 2009, usage of LARC methods increased from $2.4 \%$ to $8.5 \%$, driven primarily by the use of
IUDs [20]. While DTCA during this period was dominated by the OCPs, there has also been a substantial concurrent increase in DTCA of the LARCs, with promotional spending increasing more than a 100 -fold, from US\$411,860 in 2005 to US\$53.7 million in 2008. The association between recent increases in DTCA and LARC utilization has been previously identified by reproductive health specialists $[20,26]$; however, this study provides the first empirical evidence of the time-course and magnitude of DTCA in relation to the uptake of LARC methods. Detailed economic analysis that controls for the evolving social and clinical acceptance of LARC methods is needed to further assess the relationship between DTCA and LARC utilization.

Our study has several limitations. First, it is confined to industry expenditure on DTCA. We do not have data on promotion to health care professionals (i.e., detailing, professional journal advertising and free samples). Previous studies report key differences between professional versus DTC advertisement, with professional promotion being more prevalent and more influential on product sales than DTCA $[2,9-14]$. Our focus on DTCA expenditure alone means that we cannot assess total promotional activities for the prescription contraceptives and that we cannot determine the extent to which they employ DTCA versus other forms of promotion. Second, our study does not include data about online DTCA. However, a recent study reports that Internet promotion comprises but a small fraction of DTCA for all prescription medications, accounting for less than $5 \%$ of total DTCA in 2010 [9]. Finally, our study only quantifies dollars spent on DTCA by pharmaceutical companies and cannot examine the content of the advertisements. For example, in 2009 , the FDA required Bayer to run a US\$20 million DTCA campaign to correct prior misleading advertisements 
for Yaz [32]. Because our study does not differentiate between corrective versus promotional advertising, we combine this US\$20 million figure within the total estimates of Yaz DTCA. As such, we must be cautious when interpreting our results since our study merely reports the total dollar expenditure, regardless of whether the content is corrective or promotional. However, while there are key differences in content between these two forms of advertising, it is not yet known if the effects of corrective advertising truly differ from those of traditional promotion [33]. Furthermore, prior studies on DTCA do not differentiate between corrective and promotional advertising [8-9,11-14]; the inability to parse out corrective DTCA is an unfortunate but common limitation in the field. Future studies examining the impact of DTCA on contraceptive use should attempt to take into consideration the fraction and effects of corrective versus promotional DTCA.

This study provides the first quantitative evaluation of DTCA of the prescription contraceptives and reveals DTCA's importance as a form of promotion in this class. The DTCA of prescription contraceptives is a rich field for future investigation: further studies including data on professional promotion will be necessary to determine if the prescribing of contraceptives, compared to other prescription drugs, is more influenced by DTCA than other forms of promotion, such as detailing. This question is especially interesting given the importance of patientcentered decision-making in contraceptive care. Additional examination of DTCA trends within the context of the ACA will help characterize changes in market influences after the elimination of patient cost from medical decision-making. Finally, more extensive quantitative and qualitative research is required to ultimately determine the role of DTCA in influencing demand for - and perhaps even adherence to prescription contraceptives.

\section{References}

[1] Akintomide H. Advertising sexual health products. J Fam Plann Reprod Health Care 2010;36(1):45, http://dx.doi.org/10.1783/147118910790290920.

[2] Auton F. Direct-to-consumer advertising (DTCA) of pharmaceuticals: an updated review of the literature and debate since 2003. Econ Aff 2006;26(3):24-32, http://dx.doi.org/10.1111/j.1468-0270.2006.00646.x.

[3] Gilbody S, Wilson P, Watt I. Benefits and harms of direct to consumer advertising: a systematic review. Qual Saf Health Care 2005;14(4):246-50.

[4] Stange KC. Time to ban direct-to-consumer prescription drug marketing. Ann Fam Med 2007;5(2):101-4, http://dx.doi.org/ 10.1370/afm.693.

[5] Avorn J. Perspective: advertising and prescription drugs: promotion, education, and the public's health. Health Aff 2003, http://dx.doi.org/ 10.1377/hlthaff.w3.104.

[6] Mintzes B. Advertising of prescription-only medicines to the public: does evidence of benefit counterbalance harm? Annu Rev Public Health 2012;33(1):259-77, http://dx.doi.org/10.1146/annurev-publhealth031811-124540.

[7] Berndt E, Donohue JM. Direct-to-consumer advertising in health care: an overview of economic issues. In: Sloan FA, \& Hirschel K, editors. Incentives and choice in health care. Cambridge, MA: The MIT Press; 2008, pp. 131-62.
[8] Donohue JM, Cevasco M, Rosenthal MB. A decade of direct-toconsumer advertising of prescription drugs. N Engl J Med 2007;357(7):673-81, http://dx.doi.org/10.1056/NEJMsa070502.

[9] Kornfield R, Donohue JM, Berndt ER, Alexander GC. Promotion of prescription drugs to consumers and providers, 2001-2010. PLoS One 2013;8(3)e55504, http://dx.doi.org/10.1371/journal.pone.0055504.

[10] Berndt ER. The United States' experience with direct-to-consumer advertising of prescription drugs: what have we learned? In: Sloan FA, \& Hsieh C, editors. Pharmaceutical innovation: incentives, competition, and cost-benefit analysis in international perspective. Cambridge, UK: Cambridge University Press; 2007, pp. 174-95.

[11] Rosenthal MB, Berndt ER, Donohue JM, Epstein AM, Frank RG. Demand effects of recent changes in prescription drug promotion. Forum Health Econ Policy 2003;6(1):1-8.

[12] lizuka T, Jin GZ. Direct to consumer advertising and prescription choice. J Ind Econ 2007;55(4):771-91, http://dx.doi.org/10.1111/ j.1467-6451.2007.00329.x.

[13] Wosinska M. Just what the patient ordered? Direct-to-consumer advertising and the demand for pharmaceutical product. HBS Marketing Research Paper Nos 02-04; 2002.

[14] Donohue JM, Berndt ER. Effects of direct-to-consumer advertising on medication choice: the case of antidepressants. J Public Policy Mark 2004;23(2):115-27, http://dx.doi.org/10.1509/jppm.23.2.115.51395.

[15] Dehlendorf C, Levy K, Kelley A, Grumbach K, Steinauer J. Women's preferences for contraceptive counseling and decision making. Contraception 2013;88(2):250-6, http://dx.doi.org/10.1016/ j.contraception.2012.10.012.

[16] Kuiper H, Miller S, Martinez E, Loeb L, Darney P. Urban adolescent females' views on the implant and contraceptive decision-making: a double paradox. Fam Plann Perspect 1997;29(4):167-72.

[17] Dehlendorf C, Diedrich J, Drey E, Postone A, Steinauer J. Preferences for decision-making about contraception and general health care among reproductive age women at an abortion clinic. Patient Educ Couns 2010;81(3):343-8, http://dx.doi.org/10.1016/j.pec.2010.06.021.

[18] Finer LB, Sonfield A, Jones RK. Changes in out-of-pocket payments for contraception by privately insured women during implementation of the federal contraceptive coverage requirement. Contraception 2014;89(2):97-02, http://dx.doi.org/10.1016/j.contraception.2013.11.015.

[19] Dusetzina SB, Dalton VK, Chernew ME, Pace LE, Bowden G, Fendrick AM. Cost of contraceptive methods to privately insured women in the United States. Womens Health Issues 2013;23(2):e69-71, http:// dx.doi.org/10.1016/j.whi.2013.01.002.

[20] Finer LB, Jerman J, Kavanaugh ML. Changes in use of long-acting contraceptive methods in the United States, 2007-2009. Fertil Steril 2012;98(4):893-7, http://dx.doi.org/10.1016/j.fertnstert.2012.06.027.

[21] Winner B, Peipert JF, Zhao Q, Buckel C, Madden T, Allsworth JE, et al. Effectiveness of long-acting reversible contraception. N Engl J Med 2012;366(21):1998-2007, http://dx.doi.org/10.1056/NEJMoa1110855.

[22] Trussell J. Contraceptive failure in the United States. Contraception 2011;83(5):397-404, http://dx.doi.org/10.1016/j.contraception.2011.01.021.

[23] Spies EL, Askelson NM, Gelman E, Losch M. Young women's knowledge, attitudes, and behaviors related to long-acting reversible contraceptives. Womens Health Issues 2010;20(6):394-9, http:// dx.doi.org/10.1016/j.whi.2010.07.005.

[24] Jones RK, Biddlecom AE, Hebert L, Mellor R. Teens reflect on their sources of contraceptive information. J Adolesc Res 2011;26(4):423-46, http://dx.doi.org/10.1177/0743558411400908.

[25] Teal SB, Romer SE. Awareness of long-acting reversible contraception among teens and young adults. J Adolesc Health 2013;52(4):S35-S9, http://dx.doi.org/10.1016/j.jadohealth.2013.01.013 [Suppl.].

[26] Grimes D. Intrauterine Devices (IUDs). In: \& Hatcher R, editor. Contraceptive Technology. 19. New York: Ardent Media; 2007, pp. $117-43$.

[27] Tone A. From naughty goods to Nicole miller: medicine and the marketing of American contraceptives. Cult Med Psychiatry 2006;30(2):249-67. 
[28] Watkins ES. How the pill became a lifestyle drug: the pharmaceutical industry and birth control in the United States since 1960. Am J Public Health 2012;102(8):1462-72, http://dx.doi.org/10.2105/ AJPH.2012.300706.

[29] Avery RJ, Eisenberg MD, Simon KI. The impact of direct-to-consumer television and magazine advertising on antidepressant use. J Health Econ 2012;31(5):705-18, http://dx.doi.org/10.1016/j.jhealeco.2012.05.002.

[30] United States Department of Labor Bureau of Labor Statistics [Internet]. Available from: http://www.bls.gov/cpi/-data. Accessed 2015 Jan 10.
[31] Hansen RA, Schommer JC, Cline RR, Hadsall RS, Schondelmeyer SW, Nyman JA. The association of consumer cost-sharing and direct-toconsumer advertising with prescription drug use. Res Social Adm Pharm 2005;1(2):139-57, http://dx.doi.org/10.1016/j.sapharm.2005.03.002.

[32] Singer N. A birth control pill that promised too much. New York Times; 2009 [Feb 11: Sect. B:1].

[33] Food and Drug Administration. Agency information collection activities; proposed, collection: experimental study; examination of corrective direct-to-consumer television advertising. Fed Regist 2012;77(40):12307-8 [Docket No FDA-2012-N-0176]. 